\title{
More than Just a Game: The Power of Social Media on Super Bowl XLVI
}

\author{
Fernanda Bruno dos Santos, Jonice Oliveira \\ Graduate School in Computing Science (PPGI), Universidade Federal do Rio de Janeiro (UFRJ), Rio de Janeiro, Brasil \\ Email: fernanda.bruno@ufrj.br, jonice@dcc.ufrj.br
}

Received 24 December 2013; revised 28 January 2014; accepted 24 February 2014

Copyright (c) 2014 Fernanda Bruno dos Santos, Jonice Oliveira. This is an open access article distributed under the Creative Commons Attribution License, which permits unrestricted use, distribution, and reproduction in any medium, provided the original work is properly cited. In accordance of the Creative Commons Attribution License all Copyrights @ 2014 are reserved for SCIRP and the owner of the intellectual property Fernanda Bruno dos Santos, Jonice Oliveira. All Copyright (c) 2014 are guarded by law and by SCIRP as a guardian.

\begin{abstract}
The evolution of social media in the recent years promoted the appearance of a new category: social media based on check-in. It enables the user to define their identity through information sharing. This paper aims to show the evolution of these media highlighting the effects and changes they cause in society through Super Bowl XLVI scenario, besides indicating the important role they have for the companies and marketing.
\end{abstract}

\section{KEYWORDS}

\section{Social Media; Data Mining; Marketing; Social Networks; Gamification}

\section{Introduction}

Marketing is something that involves connecting clients with services and products. Applications based on social media develop the role of connectors between people and habits as they define communities based on what their users have in common from the information they share [1]. Due to the evolution in how consumers think, accustomed to the interactivity of the virtual world, the way of how advertisers planned their campaigns also demanded change in order to continue maintaining public interest. Companies soon realized the power that sharing possessed in order to build a kind user persona and began to make use of social media applications and check-in to release their new products and promote their brand.

As a way to engage users to share information such as location and habits, companies invested on gamification [2]. Through them, companies develop concepts to reward their customers with activities such as earning badges and virtual stickers, even without real value, are fun and create a sense of recognition within the application. This kind of interaction creates loyalty to the brand and which is very important to companies since they can work toward retaining and attracting new customers.

This paper aims to show the factors that imply the use of these applications by users and the impacts they have on the way society lives and thinks. The football event Super Bowl XLVI is used as backdrop, crossing data provided by two check-in applications: Foursquare and GetGlue. Twitter and YouTube are also used in order to analyze volume of discussion. Using these data, information was obtained in order to capture audience through the game and understand where viewers were and what was discussed during the event. This type of knowledge is invaluable for strategic planning and marketing investment in advertising, highlighting the importance that these tools have on social media scenario.

\section{Literature Review}

Social Media is a type of online media that allow users around the world to connect, share experiences and content instantly through the Internet. It is the result of the socialization process based on information represented in recent years by the extension of dialogue and how the information came to be organized through the web.

The term social media describes online technologies and practices that people use to share opinions, experiences and perspectives, and can manifest itself in different formats including text, images, audio and video [3]. 
The expansion of these media has made it easier to find friends, share ideas and opinions and information, i.e., a democratization of content where everyone participates in building a virtual community.

With the growing popularity of these platforms, companies soon realized that a good way of advertising is using social media as a way to connect people and their products. There was a transformation of acting as consumers and consequently how companies build their marketing strategies [4].

Some works, such as [5], show that it is possible to infer behavior of users through data exposed on social networks and that includes, for example, consumer habits and interests in general. This information enables the ability to identify different groups of people and create advertising strategies for different types of consumers heating the dispute between companies and brands.

According to [6], market power is extremely difficult to measure and the traditional models of competition have many limitations, such as limited flexibility due to factors such as organizational restructuring, introduction of new products in the market and even the appearance of new forms of work organization, such as virtual teams. In order to measure the degree of influence of a brand or product opinion and market polls are conducted. The first aims to accurately detect trends and positions of the various social segments while the second focuses on discovering market opportunities. Allied, they help companies to generate knowledge about the place they should take in their business.

On these matters, [7] show that traditional methods of survey are slow and costly, since they depend on people via phone or letter or in person to answer questions. It also raises issues such as anonymity. As for the cost, much of it is due to time collecting data that is usually done over the phone or on the streets, requiring an intermediary between question and interviewee. Moreover, there is the problem of reliability in the data since the survey does not only depend on the number of people interviewed, but the scientific representativeness of the sample.

Therefore, social media characterize a good source of consumer reviews regarding products and brands. They provide information about people allowing profiling of age, geographic location, by product type, for example. Or even look up from the point of view of a marketing campaign if there was a good or bad response from consumers to that product. Therefore, taking advantage of the idea of [8] which states that the great advantage of the internet is its power to provide immediate access to information, it would be possible to obtain data quickly and objectively, facilitating the analysis to be performed.

\section{Case of Study}

The Super Bowl is one of the most important sport events around the world, garnering more than 111 million viewers on the United States, the host country event, and becoming the most watched television program in the history of the country in 2012 [9]. Because of all this visibility, it also has great marketing appeal since its commercials are shown during the game with a very large number of people watching compared to the prime time audience [9]. When Super Bowl is on air a 30 second commercial costs in average 3 million dollars [9] and it is known for launching new products, so capturing data from the audience reaction creates a valuable tool to the companies to measure metrics as return on investment and user engagement.

One way to analyze the impact of an event can be held through analysis of social media data, since they allow users to share experiences instantaneously via the Internet. In order to plan the analysis, this study used Super Bowl XLVI as a backdrop and captured data from social media like Twitter, YouTube, Foursquare and GetGlue which were able to show where these viewers were, what they were thinking and what they did during the event. Using all these kind of information, it was possible to analyze the degree of attention that companies and their products attracted during the event.

Data from social media where obtained through a crawler using the API provided by the mentioned media, enabling the obtaining, among others, comments and number of views. According to data from Twitter were written more than 15 million tweets during the game compared to the 3 million in 2011 [12] showing growth of the platform. These tweets were originated from 46 different countries, showing the extent of the event. With regard to commercials, it was observed that $75 \%$ companies that exhibited advertisements made use of social media as a way to extend the brand concept and discussions on the internet. Important tools to improve the idea are based on the use of hash tags, fan pages on Facebook and links to the video on YouTube.

In order to verify whether these strategies have brought some response from the public, the final number of mentions of the brand during the event was verified, as well as the growth on the number of followers on their Twitter pages and "Like"s on Facebook. Table 1 shows the growth of some of the followers companies that launched advertisements during the Super Bowl, as well as tweets mentioning the brand. Through these data, it is possible to note that advertisements generated some kind of public interest, since people start to receive in their Twitter accounts updates about products and information that the company think its relevant to users and custumers. The fact that the companies are able to attract consumer's attention is of great importance since they are responsible for spreading the brand related information through endorsements and retweets from his followers. 
Table 1. Data from twitter.

\begin{tabular}{ccccc}
\hline dnarB & $\begin{array}{c}\text { oFllowers } \\
\text { before }\end{array}$ & $\begin{array}{c}\text { ewolloFrs } \\
\text { after }\end{array}$ & oitneMns & worGth \\
\hline Bridgestone & 687 & 3.852 & 23.789 & $461 \%$ \\
E*Trade & 4.437 & 11.006 & 43.783 & $148 \%$ \\
ispeP & 5.968 & 7.148 & 14.494 & $20 \%$ \\
sotiroD & 2.761 & 3.217 & 47.223 & $17 \%$ \\
Volkswagen & 10.992 & 12.348 & 32.689 & $12 \%$ \\
\hline
\end{tabular}

As regards to social media based on check in, Foursquare that has 10 million users, made available for those who performed check in at bars and restaurants during Super Bowl a badge called "Super Swarm Sunday". According to the [11], 350,000 people earned the badge performing check ins at 2.500 different places in 117 different countries. 3000 of them performed check ins on the stadium where Super Bowl was held, which had the capacity of 68,000 seats. Therefore, it can be concluded in relation to the this group of users that the event, seen as typically American, attracted considerable attention from foreign people showing how American culture has spread around the world.

GetGlue, according to the [12], who owned about 1 million users, registered 160,000 check ins during the event. The high number of check-ins can be explained by the existence of exclusive virtual stickers for the event, one for each stage of Super Bowl, which when collected, could be sent to the user by snail mail in physical copies. 23,000 comments generated by the check ins had mentions of brands that were advertising, representing $15 \%$ the check ins made. Besides stickers, companies launched contests through GetGlue encouraging discussion about their products and number of check ins.

The advertisements that aired during the event were provided by advertisers on YouTube. The strategy was used by brands to launch extended versions of the commercials during the Super Bowl, encouraging viewers to broaden their experience accessing social media. When comparing the total views of the most viewed video on YouTube at the time, which had 457 million views (YouTube Charts, 2012) and the videos aired on Super Bowl it is possible to infer that in just 3 days on average, 18 million views, representing $3 \%$ of the video most viewed. Taking into account that the video took 21 months to get to this position, Super Bowl commercials, with the average of 6 million page views per day, they would take only 2,5 months to reach this level.

All these data demonstrate how companies can use social media to obtain advantages in terms of marketing, maximizing discussions about their products and brands, not only restricting the television media. As presented here, users have proved to be receptive to new ways of marketing, and attracted to new and creative strategies of advertising. They were also involved by the atmosphere created around events and increasingly willing to share their opinions, preferences and even their habits and routines with applications they trust.

\section{Conclusion}

In order to make marketing and social media applications to express its full potential is still important to invest on game mechanics, so as reinvent products and services are produced, consumed and how consumers interact with it. To make it possible, it is necessary that these applications can be smarter, connecting people to move simpler and delivering valuable content and contextualized them. Besides that, it is important to improve the ability to attract more users. In order to achieve that, these applications need to be more intuitive and capable of offer even richer and essential experiences for its users. From the point view of business, they have to reach opportunities to increase the number of consumers. However, to get there, they need to educate them about the pros of using these applications and creating and disseminating new strategies.

\section{Acknowledgements}

We would like to thank CNPq, CAPES, and FAPERJ for their support, specially by the support provided by the projects "INCT para Controle do Câncer" (CNPq 573806/ 2008-0 e FAPERJ E26/170.026/2008) and "Projeto Universal: CLOTO: Composição, Mineração, Análise e Predição de RedesSociaisUtilizando Dados LigadosAbertos e Contextualizados" (CNPq 487239/2012-1), by the grants "JovemCientista do Nosso Estado" (Young Researcher of Rio de Janeiro, FAPERJ: E_23/2013) and "ProdutividadeemPesquisa-Nível 2" (Productivity in Research-Level 2, CNPq: 308219/2010-4).

\section{REFERENCES}

[1] C. Ververidis and G. Polyzos, "Mobile Marketing Using Location Based Service,” In International Conference on Mobile-Business, Athens, 2002.

[2] J. Lindqvist, et al., "I'm the Mayor of My House: Examining Why People Use Foursquare-A Social-Driven Location Sharing Application,” In Conference on Human Factors in Computing Systems, ACM, New York, 2011, pp. 2409-2418.

[3] B. Solis and D. Breakenridge, "Putting the Public Back in Public Relations: How Social Media Is Reinventing the Aging Business of PR,” FT Press, 2009.

[4] K. Zhang, "A Competitive Analysis of Web 2.0 Communities: Differentiation with User-Generated Content," 2011.

[5] C. Tang, et al., "What's in a Name: A Study of Names, 
Gender Inference, and Gender Behavior in Facebook,” In Proceedings of DASFAA Workshops, 2011, pp. 344-356.

[6] C. Pleatsikas and D. Teece, "The Analysis of Market Definition and Market Power in the Context of Rapid Innovation,” International Journal of Industrial Organization, Vol. 19, No. 5, 2001, pp. 665-693.

http://dx.doi.org/10.1016/S0167-7187(00)00088-6

[7] J. Zhu, et al., "Aspect-Based Opinion Polling from Customer Reviews," IEEE Transactions on Affective Computing, Vol. 2, No. 1, 2011, pp. 37-49.

http://dx.doi.org/10.1109/T-AFFC.2011.2

[8] C. Shapiro and H. Varian, "Information Rules: A Strategic Guide to the Network Economy,” Harvard Business School Press, Boston, 1999.

[9] Reuters Website, "Super Bowl TV Audience Reaches Record 111.3 Million,” 2012. http://www.reuters.com/article/2012/02/06/us-superbowltv-idUSTRE8151Q020120206

[10] B. Stelter, "A Super Bowl Where Viewers Let Their Fingers Do the Talking,” The New York Times, 2012. http://mediadecoder.blogs.nytimes.com/2012/02/06/a-sup er-bowl-where-viewers-let-their-fingers-do-the-talking/? $\mathrm{php}=$ true \&_type=blogs \&_r $=0$

[11] Foursquare Blog-Avaiableon, 2012. https://www.facebook.com/foursquare/posts/2920634241 $\underline{81556}$

[12] GetGlue Blog, “GetGlue Guide to Super Bowl”, 2012. http://blog.getglue.com/?p=10388

[13] YouTube Charts, 2013. https://www.youtube.com/charts 